\title{
Effect of a Parent-Focused Intervention for Autistic Children on Parenting Stress at Assiut City
}

\author{
Aly, Sh., E ; Ibrahim , H., D; Askar , G., A \& Bayomi Soad Sayed. \\ Departments of Community Health Nursing- Faculty of Nursing- Assiut University \\ Pediatrics Medicine- Faculty of Medicine-Assiut University
}

\begin{abstract}
:
Autism is a neurological disorder characterized by qualitative impairments in social interaction, qualitative impairments in communication, and restricted repetitive, stereotyped patterns of behavior, interests, and activities. Autistic Spectrum Disorders (ASDs) are relatively common without known etiology can be found in $80-90 \%$ of cases. The study aimed to evaluate the effect of a parent-focused intervention for autistic children on parenting stress at Assiut City. Subjects and methods: The study was Quasi-experimental research design. It was conducted in all autism centers at Assiut city which includes 7 centers and included 73 parents who agreed to participate in this study selected by convenient sample; this sample included 47 mothers and 26 fathers. The study included three tools: - a structured interview sheet, parents' knowledge assessment about autism, and parenting stress scale. The main results of the study indicated that there was highly statistically significant differences between mothers' and fathers' knowledge about autism $(P$-value $=0.000)$ in pre, immediate post-test and follow-up. Moreover there was highly statistically significant difference between Parental stress scale for mothers and fathers in pre-test and immediate post-test respectively $(P$-value $=0.000 * \& 0.002 *)$ while no statistically significant difference between pre-test and follow-up respectively $(P$-value $=0.152 \& 0.417)$. The study Concluded that there was improvement of parents' knowledge about autism in immediate post-test and follow up; moreover the parents' stress level was decreased in immediate post-test than pre-test while the stress level again slightly increase during follow up test. The study recommended that: Nursing staff should play a much greater role in supporting parents and providing them with important information through pediatrics clinics, Maternal and Child Health Centers (MCH), and others.
\end{abstract}

\section{Key wards: Autism - Autism Spectrum Disorders - Parenting stress}

\section{Introduction}

Autism is one of five disorders that falls under the umbrella of Pervasive Developmental Disorders (PDD), (PDD) a category of neurological disorders characterized by severe and pervasive impairment in several areas of development). It is defined by the Autism Society of America (ASA) as: "Autism is a complex developmental disability that typically appears during the first three years of life and is the result of a neurological disorder that affects the normal functioning of the brain, impacting development in the areas of social interaction and communication skills. Both children and adults with autism typically show difficulties in verbal and nonverbal communication, social interactions, and leisure or play activities (Johnson \& Myers, 2007and Sadock \& Sadock, 2010).

Autism belongs to a collection of developmental disorders known as the Autism Spectrum Disorders (ASDs). A spectrum disorder is a group of disorders with similar features; while one person may have mild symptoms, another might have more severe ones. There are also differences in the nature of the symptoms themselves and when they are likely to first appear (American Psychiatric Association (APA), 2000 and Levy et al, 2009).
In Egypt there is no enough researches focused on this disorder and no documented researches advertiser and definite lucid about epidemiology of autism but extrapolated Prevalence is 152,234 from 76, 117, and 4212 (CDC, 2007, US Census Bureau, 2008 and Bowden \& Greenberg, 2010).

Much public attention has focused on the increased number of children diagnosed with autism in recent year; the search for possible causes of autism has led to heated controversy. The different potential causes of autism have strong proponents, some of the suggested causes are:- genetic, Biological, perinatal, neuroanatomical, immunological, biochemical, environmental, psychosocial and family factors (Kliegman etal, 2007, Bowden \& Greenberg, 2010 and National Autism Association, 2010).

Clinical features of the disorder should be present before the age of 3 years, approximately $20 \%$ of parents report relatively normal development until 1 or 2 years followed by a steady or sudden decline. Parents usually first become concerned when they realize that their child's expressive language is delayed. Indeed, this has been the historical hallmark of the disorder and will likely continue to be so as these deficits are easily recognized. Although earlier social skill deficit are now better known in 
professional circles, they are not as easily recognized by parents (Hales \& Yudofsky, 2004).

The clinical manifestations of autism are divided into three categories Inability to relate to other (social impairment), Inability to communicate with others (communication impairment), Obviously limited activities and interest (restricted repetitive and stereotyped patterns of behavior) (Klossner and Hatfield, 2010).

The possible indicators or early signs of ASDs are; does not babble, point, or make meaningful gestures by 1 year of age, does not speak one word by 16 months, does not combine two words by 2 years, does not respond to name, and Loses language or social skills. Others indicators include:- avoid eye contact and want to be alone, doesn't seem to know how to play with toys, excessively lines up toys or other objects, is attached to one particular toy or object, doesn't smile, at times seems to be hearing impaired, may prefer to be by him/herself, repeat or echo words or phrases said to them, or repeat words or phrases in place of normal language (echolalia), have trouble expressing their needs using typical words or motions, no fear of danger, over or under sensitivity to pain, repeat actions over and over again, have trouble adapting to changes in routine, and have unusual reactions to the way things smell, taste, look, feel, or sound ( Autism Society, 2008, CDC, 2010 and Bowden \& Greenberg, 2010)

The diagnosis of autism often leads families to make significant changes within the family unit, and family members must adjust to the special needs that a child with Autism requires. In particular, parents must adjust to increased levels of stress. Parents of children with ASDs are consistently found to have higher levels of parenting stress than parents of children with other disorders (Autism Information Center, 2008).

There are no medications or treatments available to cure autism. Each child's treatment is individualized; behavioral and communication therapies are very important. Children with ASDs respond very well to highly structure educational environments. Stimulants may be used to control hyperactivity, and antipsychotic medications are sometimes helpful in children with repetitive and aggressive behaviors. Many families are drawn to the use of complementary and alternative medical therapies in attempts to treat their autistic children; these therapies have not been scientifically proven to improve autism. The goal of the therapeutic management is for the child to reach optimal functioning within the limitations of the disorder (Videbeck, 2008 and Burns et al, 2009).

The role of community health nurse who comes from contact with families through work in well- child or immunization clinics, it is important to establish relationships that are responsive to the methods of the person and family for dealing with the autistic children and nurses should be well informed about the numerous community resources for these children (Allender et al, 2010).

\section{Aim of the study:}

The aim of this study to evaluate the effect of a parent-focused intervention for autistic children on parenting stress at Assiut City.

\section{Subject And Methods Research Design}

Quasi-Experimental research design was used in this study to implement and evaluate the educational program (intervention) for parents of autistic children at Assiut city.

\section{Setting:}

This study was carried out in all autism centers at Assiut city which includes 7 centers namely; Mental Abilities Clinic, Al-saad Center, Social Rehabilitation Association, Women's Association, Kian Association, The Future center, and Awladna Center.

\section{Sample:}

The subject includes all parents (mothers and fathers) of Autistic children from both sex (male and female) aged from 3-17 years within one year from starting of data collection selected by convenient sample. The total number of autistic children was 62 ; but 47 children were included in this study due to parents' agreement. Moreover the total numbers of parents were 73 who agreed to participate in this study; these numbers included 47 mothers and 26 fathers.

\section{Tools of data collection: \\ It included three tools:- \\ Tool I:-}

A structured interview sheet was constructed after reviewing the relevant literature to elicit information. It included Socio-demographic characteristics, family history, obstetric history of autistic children mothers', medical and social history of the child and his family. This tool was done only one time.

\section{Tool II:-}

This tool included parents' knowledge assessment about autism which includes; definition of autism, different name for it, age at appearance of symptoms, gender distribution, categories of impairment for autism, causes, signs and symptoms, methods of diagnosis and treatment for autism, allowance and not allowance food for autistic child.

Parents' knowledge assessment about autism was developed by the researcher and supervisors; to ensure the validity of this tool checked and revised by 
panel of seven experts from community health and psychiatric nursing and medical staff at Assiut University who reviewed the instrument for clarity, relevance, comprehensiveness, understanding and applicability.

This tool was done three times for the same parent, the first time before intervention, the second time immediately after the educational program (intervention) and the third time after three months from the educational program (intervention).

A scoring system was designed for the assessment of parents' knowledge contains of 11 questions divided into 4 categories; the first category placed under the questions of definition of autism, different names of autism, age at appearance of symptoms, gender distribution, impairment pattern of autism, and risk factors of autism, the second category placed under the question of symptoms of autism, the third category placed under the questions of methods of diagnosis and treatment for autism and finally the fourth category placed under the questions of allowed and not allowed foods for autistic children, the total grade of knowledge equal (66); a score of 1 was given for each correct answer and a score of zero was given for an incorrect answer and I don't know.

The total score knowledge was determined as Hassan, 2010 who estimated the answer by taking points as the following:

- Less than 50 unsatisfactory - 50 and above satisfactory

\section{Tool III:}

This tool included parenting stress scale; The Parental Stress Scale (PSS) is an 18-item, 5-point, Likert-type self-reporting instrument that is used to assess parental stress for both mothers and fathers (parents) of children with and without clinical problems. This scale is used to find relationships among research variables or comparison between them (Berry \& Jones, 1995).

Respondents are asked to agree or disagree with items in terms of their typical relationship with their child and the responses were on a five-point scale: strongly disagree (1), disagree (2), undecided (3), agree (4), and strongly agree (5). The 8 positive items $1,2,5,6,7,8,17$, and 18 are reverse scored so that possible scores on the scale can range between "1890". Higher scores on the scale indicate greater stress (Berry \& Jones, 1995). This tool was done three times for the same parent, the first time before intervention, the second time immediately after the educational program and the third time after three months from the educational program.

Parenting Stress Scale (PSS) translate into Arabic form and to ensure the validity of this tool checked and revised by panel of seven experts from community and psychiatric nursing and medical staff at Assiut University who reviewed the instrument for clarity, relevance, comprehensiveness, understanding and applicability.

\section{The educational program (Intervention) description:}

The educational program has been developed by the researcher based on review of relevant literature, available resources, and revision from professor of community health nursing and assistant professor in Assiut University as well as expert in the field of pediatrics neurology. According to the opinions of experts necessary modifications was made done.

\section{General objectives of the program:}

1)To assess the parents knowledge about autism

2)To provide the parents with right knowledge about autism and the different method of treatment

3) To decrease parent stress level.

4)Learn the parents how to coping with their autistic children.

5) To motivate the parents toward modification of their behavior and practice about their Autistic children.

\section{Assessment:}

Based on the experience and general knowledge of the researcher about lack of knowledge about autism; the researcher developed this program to improve parent's knowledge and teach them how to deal with autistic children. Also based on pre-test assessment of parent's knowledge and practice toward autism which denotes knowledge deficit and unsatisfactory practice; so the program, media were prepared.

\section{Planning stage:}

The arrangement of conducting the program done during this stage; the sessions and time of the program decided. The study sample (parents) were divided into 12 groups in a variety of numbers ranged between (3-8) parents in each group according to the numbers of sample in each place. Other facilities were checked and arranged during this phase as the teaching place, audiovisual aids, handout etc.......

Teaching Time: the time of teaching was decided according to the attendance of parents in the center and the coordination between the researcher and participants.

Teaching place the program was conducted in the classes or training room in each center; those arrangements done with the director of each center.

Teaching methods and materials: It was important before implementing the educational program to prepare simple teaching methods to be used; as lecture, discussion, and brainstorming. The media as power point presentation, blackboard, picture and handouts. 


\section{Implementation stage:}

The educational program was conducted in one year; this program continued for seven days to complete the program content for each group. The total numbers of sessions was (11), each day one or two session was to be given according to the planned course, after completed the program content followed by an immediate post-test and finally follow up test after three months from application of the program.

Evaluation stage: the evaluation was done through:

A) Post-test which done immediately after implementing and completing the course to assess parent's knowledge and practice.

B) Follow up which was done after 3 months of completing the educational program.

\section{Ethical Consideration:}

The purpose of this study was explained for all participants and directors of the centers individually. The parents have ethical rights to agree or refuse to participate in the study; oral consent was taken from all parents who participated in the study to ensure active participation and cooperation during implementing of the program and informed that the information obtained will be confidential and used only for the purpose of the study.

\section{Data collection:}

An official approval letters were obtained from the Dean of Faculty of Nursing, Assiut University to directors of autism centers in Assiut City. These letters includes a permission to carry out the study and explained the purpose and nature of the study. Interviews were conducted individually with parents of the children after getting their oral consent to participate and after explaining to them the purpose of the study. They were reassured about the confidentiality of the obtained information. A pilot study was conducted before starting data collection on (6) parents who was included in the sample for nonexistence of any modification in the sheet. The aim of pilot study was to test the clarity of the tool and to estimate the time required to fill the sheet.

\section{Field Work:}

Before the application of the program, the researcher introduced herself to participants to establish the necessary rapport and gain their attention and interest, an orientation to the program and its purpose was done and the parents were informed about the time and place of session taken; Pre-test was used before the implementing educational program to assess the parents' knowledge and parent stress level, each session started by a summary about what was given during the previous sessions and the objectives of the new topics. The post test for the parent was implemented by repeating the same format of the pretest to determine the effect of the implemented the program. Finally, follow up test done after 3 months from the program. The educational program conducted in the period from first of April 2011 until the end of April 2012.

\section{Data Analysis}

The data obtained were reviewed, prepared for computer entry, coded, analyzed and tabulated. Descriptive statistics (i.e., frequencies, percentage, mean, standard deviation, etc) were done using computer program SPSS version 11. Chi-square and T-test, test used to compare differences in the distribution of frequencies among different groups. It is considered significant when P-values were less than 0.05 or $(\mathrm{P}<0.05)$.

\section{Results:}

Table (1): Distribution of the studied children regarding to Socio-demographic characteristics at Assiut City, 2012 (No. = 47).

\begin{tabular}{|l|c|c|}
\hline Socio-demographic Characteristics & No. $\mathbf{( 4 7 )}$ & $\mathbf{\%}$ \\
\hline Age: & & 48.9 \\
\hline$<6$ years & 24 & 51.1 \\
\hline 6-17 years & 23 & \\
\hline Mean \pm SD (Range) & \multicolumn{2}{|c|}{$6.08 \pm 2.60(3-15)$} \\
\hline Sex: & 34 & 72.3 \\
\hline Male & 13 & 27.7 \\
\hline Female & & 19.1 \\
\hline Residence: & 9 & 80.9 \\
\hline Rural & 38 & \\
\hline Urban & & \\
\hline
\end{tabular}




\begin{tabular}{|c|c|c|}
\hline Socio-demographic Characteristics & No. $=(47)$ & $\%$ \\
\hline $1-2$ & 23 & 48.9 \\
\hline 3 or more & 24 & 51.1 \\
\hline Mean \pm SD (Range) & \multicolumn{2}{|c|}{$2.72 \pm 1.10(1-6)$} \\
\hline \multicolumn{3}{|l|}{ Birth order: } \\
\hline First & 22 & 46.8 \\
\hline Second & 11 & 23.4 \\
\hline Third & 8 & 17.0 \\
\hline Fourth or more & 6 & 12.8 \\
\hline \multicolumn{3}{|l|}{ Age of child at diagnosis: } \\
\hline First year & 14 & 29.8 \\
\hline Second year & 10 & 21.3 \\
\hline Third year & 14 & 29.8 \\
\hline Above of this & 9 & 19.1 \\
\hline \multicolumn{3}{|l|}{ Father's education: } \\
\hline Basic education & 2 & 4.3 \\
\hline Secondary education & 1 & 2.1 \\
\hline Technical institutions & 14 & 29.8 \\
\hline University & 30 & 63.8 \\
\hline \multicolumn{3}{|l|}{ Mother's education: } \\
\hline Basic education & 1 & 2.1 \\
\hline Secondary education & 8 & 17.0 \\
\hline Technical institutions & 9 & 19.1 \\
\hline University & 29 & 61.7 \\
\hline \multicolumn{3}{|l|}{ Father's occupation: } \\
\hline Employee & 35 & 74.5 \\
\hline Skilled worker & 10 & 21.3 \\
\hline Not working & 2 & 4.3 \\
\hline \multicolumn{3}{|l|}{ Mother's occupation: } \\
\hline Employee & 26 & 55.3 \\
\hline Housewife & 21 & 44.7 \\
\hline
\end{tabular}

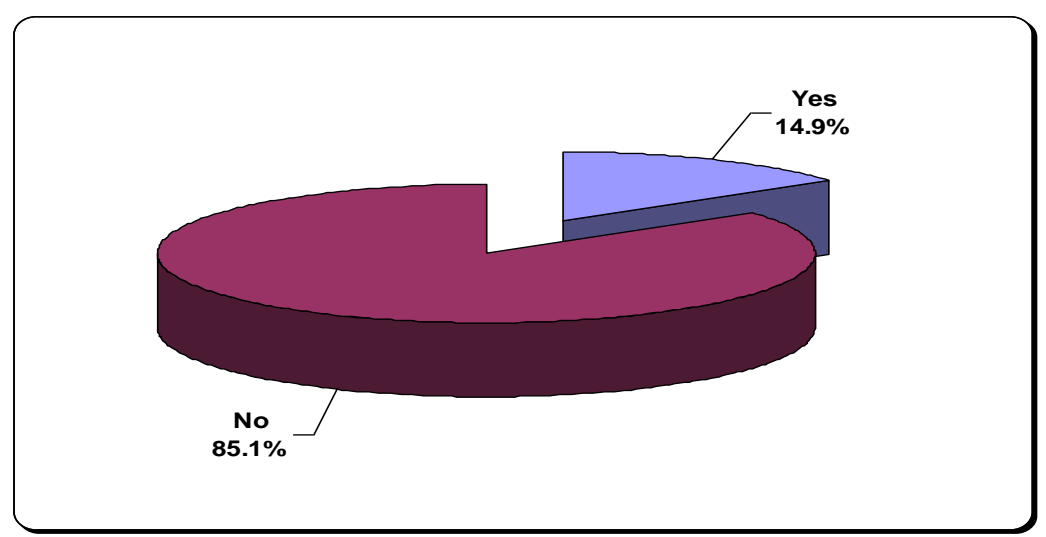

Figure (1):- Distribution of the studied children related to consanguinity degree between parents at Assiut City, 2012 (No. =47) 


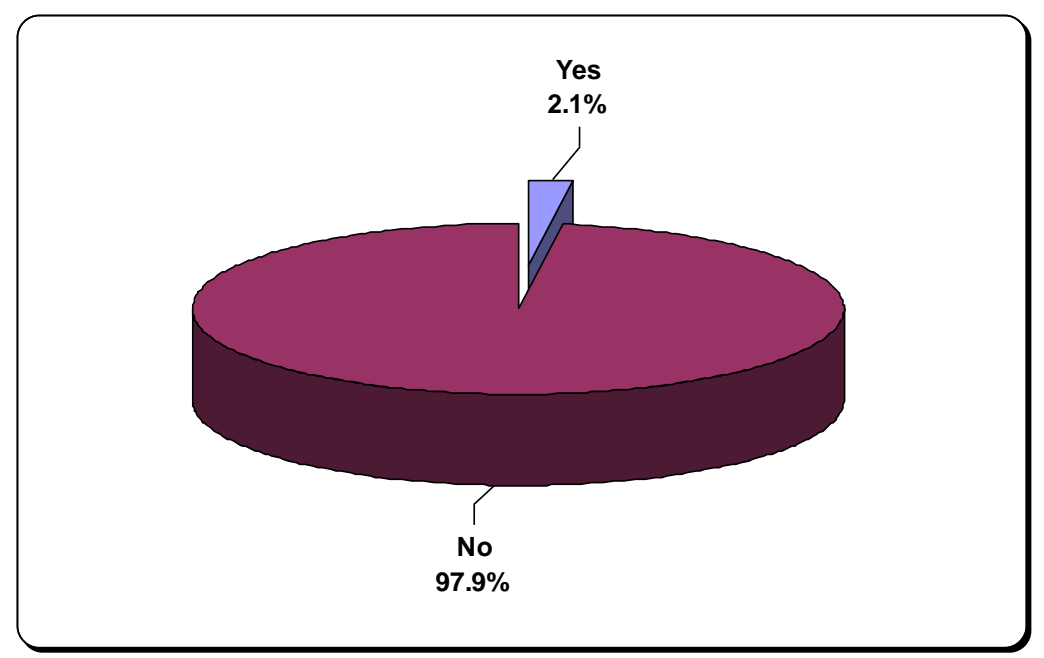

Figure (2): Distribution of the studied children related to family history of Autism at Assiut City, 2012 (No. =47).

Table (2): Distribution of the studied children mothers' regarding to risk factors at Assiut City, $2012($ No. $=47)$.

\begin{tabular}{|c|c|c|}
\hline Items & No. $=(47)$ & $\%$ \\
\hline \multicolumn{3}{|l|}{ History of eclampsia: } \\
\hline Yes & 2 & 4.3 \\
\hline No & 45 & 95.7 \\
\hline \multicolumn{3}{|c|}{$\begin{array}{l}\text { Drugs used during pregnancy without physician } \\
\text { consultation: }\end{array}$} \\
\hline Yes & 7 & 14.9 \\
\hline No & 40 & 85.1 \\
\hline \multicolumn{3}{|c|}{ Types of drugs taking during pregnancy } \\
\hline Analgesic & 7 & 100.0 \\
\hline Others & 0 & 0.0 \\
\hline \multicolumn{3}{|l|}{ History of exposure to Radiology: } \\
\hline Yes & 24 & 51.1 \\
\hline No & 23 & 48.9 \\
\hline \multicolumn{3}{|l|}{ Type of Radiology $\neq:$} \\
\hline X-ray & 1 & 4.2 \\
\hline Ultrasound & 21 & 87.5 \\
\hline Both & 2 & 8.3 \\
\hline \multicolumn{3}{|c|}{ Number of exposure to Radiology $\neq$ : } \\
\hline $1-3$ time & 13 & 54.2 \\
\hline 4 or more & 11 & 45.8 \\
\hline Mean \pm SD (Range) & \multicolumn{2}{|c|}{$3.83 \pm 1.66(2-8)$} \\
\hline \multicolumn{3}{|l|}{ Age of pregnancy: } \\
\hline$<30$ years & 32 & 68.1 \\
\hline $30-35$ years & 12 & 25.5 \\
\hline
\end{tabular}

$\neq$ Number of studied children mothers' equal 24 
Table (3): Distribution of the studied children regarding to risk factors at Assiut City, 2012 (No. = 47).

\begin{tabular}{|c|c|c|}
\hline Items & No. $=(47)$ & $\%$ \\
\hline \multicolumn{3}{|c|}{$\begin{array}{l}\text { The child had other disability or congenital anomalies with } \\
\text { autism: }\end{array}$} \\
\hline Yes & 4 & 8.4 \\
\hline No & 43 & 91.6 \\
\hline \multicolumn{3}{|l|}{ Types of disability $\pm:$} \\
\hline Dawn's syndrome & 2 & 4.2 \\
\hline Mental Retardation (MR) & 2 & 4.2 \\
\hline \multicolumn{3}{|l|}{ Admission to incubator: } \\
\hline Yes & 8 & 17.0 \\
\hline No & 39 & 83.0 \\
\hline \multicolumn{3}{|l|}{ Duration of admission $\neq$ : } \\
\hline$<5$ days & 1 & 12.5 \\
\hline $1-2$ weeks & 6 & 75.0 \\
\hline$>2$ weeks & 1 & 12.5 \\
\hline \multicolumn{3}{|c|}{ Leave the child watching T.V under the age of 3 years: } \\
\hline Yes & 24 & 51.1 \\
\hline No & 23 & 48.9 \\
\hline \multicolumn{3}{|l|}{ Period of watching T.V dailym: } \\
\hline$<3$ hours & 9 & 37.5 \\
\hline $3-6$ hours & 11 & 45.8 \\
\hline$>6$ hours & 4 & 16.7 \\
\hline \multicolumn{3}{|l|}{ Type of programn: } \\
\hline Songs & 11 & 45.8 \\
\hline Cartoon & 1 & 4.2 \\
\hline Songs and Cartoon & 12 & 50.0 \\
\hline \multicolumn{3}{|l|}{ Good relationship between parents: } \\
\hline Yes & 33 & 70.2 \\
\hline No & 14 & 29.8 \\
\hline
\end{tabular}

\pm Number of studied children equal 4

$\neq$ Number of studied children equal 8

- Number of studied children equal 24

Table (4): The relation between total score of mother's knowledge about Autism in pre, post and follow-up test at Assiut city, $2012($ No.= 47)

\begin{tabular}{|c|c|c|c|c|c|c|}
\hline \multirow{2}{*}{ Score of mother's knowledge } & \multicolumn{2}{|c|}{ Pre-test } & \multicolumn{2}{|c|}{ Immediate Post-test } & \multicolumn{2}{|c|}{ Follow-up test } \\
\hline & No. & $\%$ & No. & $\%$ & No. & $\%$ \\
\hline Satisfactory & 0 & 0.0 & 37 & 78.7 & 12 & 25.5 \\
\hline Unsatisfactory & 47 & 100.0 & 10 & 21.3 & 35 & 74.5 \\
\hline Test & \multicolumn{6}{|c|}{ Chi-square test $\left(\right.$ Chi $\left.=\mathrm{X}^{2}\right)$} \\
\hline $\begin{array}{l}\text { P-value }{ }^{I} \text { between pre-test and } \\
\text { post-test }\end{array}$ & \multicolumn{6}{|c|}{$0.000^{*}$} \\
\hline $\begin{array}{l}P \text {-value between pre-test and } \\
\text { follow-up }\end{array}$ & \multicolumn{6}{|c|}{$0.016^{*}$} \\
\hline
\end{tabular}

$* P$-value is highly statistically significant difference at $\leq 0.001$ 
Table (5): The relation between total score of father's knowledge about Autism in pre, post and follow-up test at Assiut city, 2012 (No. =26).

\begin{tabular}{|c|c|c|c|c|c|c|}
\hline \multirow[t]{2}{*}{ Score of father's knowledge } & \multicolumn{2}{|c|}{ Pre-test } & \multicolumn{2}{|c|}{$\begin{array}{c}\text { Immediate Post- } \\
\text { test }\end{array}$} & \multicolumn{2}{|c|}{$\begin{array}{l}\text { Follow-up } \\
\text { Test }\end{array}$} \\
\hline & No. & $\%$ & No. & $\%$ & No. & $\%$ \\
\hline Satisfactory & 0 & 0.0 & 12 & 46.2 & 10 & 38.4 \\
\hline Unsatisfactory & 26 & 100.0 & 14 & 53.8 & 16 & 61.6 \\
\hline Test & \multicolumn{6}{|c|}{ Chi-square test $\left(\mathrm{Chi}=\mathrm{X}^{2}\right)$} \\
\hline $\begin{array}{l}\text { P-value }{ }^{I} \text { between pre-test and post- } \\
\text { test }\end{array}$ & \multicolumn{6}{|c|}{$0.000^{*}$} \\
\hline $\begin{array}{l}P \text {-value } e^{2} \text { between pre-test and } \\
\text { follow-up }\end{array}$ & \multicolumn{6}{|c|}{$0.019^{*}$} \\
\hline
\end{tabular}

$* P$-value is highly statistically significant difference at $\leq 0.001$

Table (6): The relation between total score of mother's knowledge, and their education, and occupation level at Assiut city, 2012 (No. =47).

\begin{tabular}{|c|c|c|c|c|}
\hline Items & Mean \pm SD & Range & Test & P-value \\
\hline \multicolumn{3}{|l|}{ Mothers' education: } & \multirow{6}{*}{$\begin{array}{l}\text { Independent } \\
\text { samples } \\
\text { t-test }\end{array}$} & \multirow{3}{*}{$0.000^{*}$} \\
\hline $\begin{array}{l}\text { Low level of education } \\
\text { (basic, secondary, and technical ducation) }\end{array}$ & $5.78 \pm 5.39$ & $2-25$ & & \\
\hline $\begin{array}{l}\text { High education (university and post } \\
\text { graduate degree) }\end{array}$ & $12.69 \pm 5.65$ & $4-29$ & & \\
\hline \multicolumn{3}{|l|}{ Mothers' occupation: } & & \multirow{3}{*}{$0.014 *$} \\
\hline Employee & $12.04 \pm 7.44$ & $2-29$ & & \\
\hline Housewife & $7.35 \pm 3.84$ & $3-13$ & & \\
\hline
\end{tabular}

$* P$-value is highly statistically significant difference at $\leq 0.001$

$* P$-value is statistically significant difference at $\leq 0.05$

Table (7): The relation between total score of father's knowledge, and their education, and occupation level at Assiut city, 2012 (No. =26).

\begin{tabular}{|c|c|c|c|c|}
\hline Items & Mean \pm SD & Range & Test & P-value \\
\hline Fathers' education: & & & \multirow{6}{*}{$\begin{array}{l}\text { Independent } \\
\text { samples } \\
\text { t-test }\end{array}$} & \multirow{3}{*}{$0.052 \neq$} \\
\hline $\begin{array}{l}\text { Low level of education } \\
\text { ( basic, secondary, and technical } \\
\text { education) }\end{array}$ & $3.90 \pm 2.42$ & $1-10$ & & \\
\hline $\begin{array}{l}\text { High education (university and post } \\
\text { graduate degree) }\end{array}$ & $8.25 \pm 6.39$ & $2-24$ & & \\
\hline \multicolumn{3}{|l|}{ Fathers' occupation: } & & \multirow{3}{*}{$0.491 \neq$} \\
\hline Employer & $6.53 \pm 4.88$ & $1-19$ & & \\
\hline Skilled worker & $6.71 \pm 7.67$ & $2-24$ & & \\
\hline
\end{tabular}

$\neq P$-value is un-statistically significant difference at $>0.05$ 
Paired samples $t$ - test

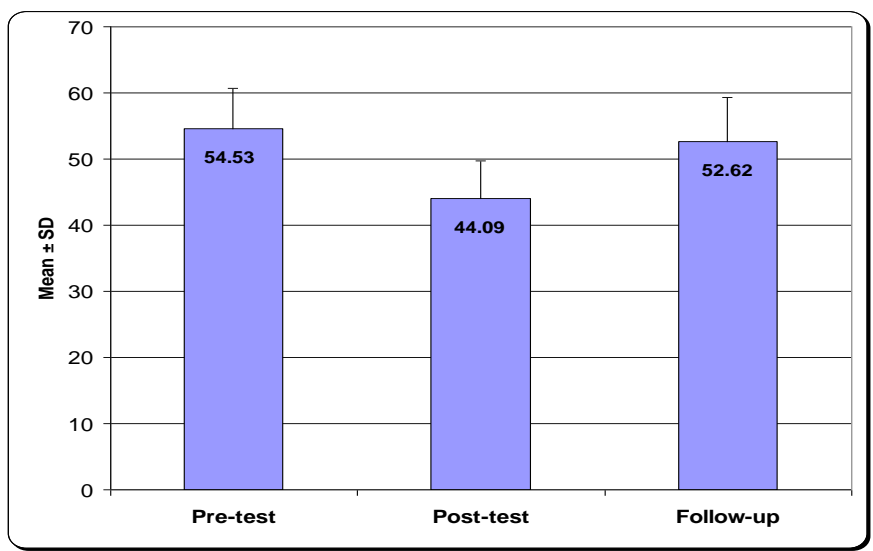

$P$-value ${ }^{l}$ is highly statistically significant difference between pre-test and post-test

$P$-value ${ }^{2}$ is un-statistically significant difference between pre-test and follow-p

Figure (3): The relation between Parental Stress Scale for mothers in pre, post and follow-up test at Assiut city, 2012 (No. $=47)$.

Paired samples $t$ - test

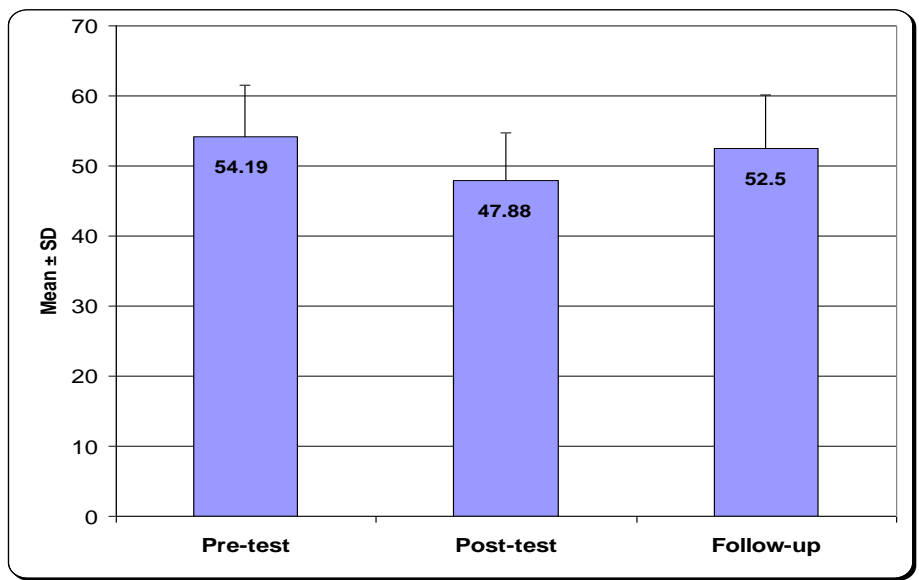

$P$-value ${ }^{l}$ is statistically significant difference between pre-test and post-test

$P$-value ${ }^{2}$ is un-statistically significant difference between pre-test and follow-up

Figure (4): The relation between Parental Stress Scale for fathers in pre, post and follow-up test at Assiut city, 2012 (No. =26).

Table (8): The relation between Parent stress for mothers, and their education and occupation level at Assiut city, 2012 (No. =47).

\begin{tabular}{|c|c|c|c|c|}
\hline \multirow{2}{*}{ Items } & \multicolumn{2}{|c|}{ Parent Stress } & \multirow{2}{*}{ Test } & \multirow{2}{*}{ P-value } \\
\hline & Mean \pm SD & Range & & \\
\hline \multicolumn{3}{|l|}{ Mothers' education: } & \multirow{6}{*}{$\begin{array}{l}\text { Independent } \\
\text { samples } \\
\text { t-test }\end{array}$} & \multirow{3}{*}{$0.123 \neq$} \\
\hline $\begin{array}{l}\text { Low level of education } \\
\text { ( basic, secondary, and technical education) }\end{array}$ & $56.28 \pm 5.76$ & $44-64$ & & \\
\hline $\begin{array}{l}\text { High education (university and post graduate } \\
\text { degree) }\end{array}$ & $53.45 \pm 6.15$ & $41-68$ & & \\
\hline \multicolumn{3}{|l|}{ Mothers' occupation: } & & \multirow{3}{*}{$0.969 \neq$} \\
\hline Employee & $54.58 \pm 5.72$ & $42-64$ & & \\
\hline Housewife & $54.65 \pm 6.81$ & $41-68$ & & \\
\hline
\end{tabular}

$\neq P$-value is un-statistically significant difference at $>0.05$ 
Table (9): The relation between Parent stress for fathers, and their education and occupation level at Assiut city, 2012 (No. =26).

\begin{tabular}{|c|c|c|c|c|}
\hline \multirow{2}{*}{ Items } & \multicolumn{2}{|c|}{ Parent Stress } & \multirow{2}{*}{ Test } & \multirow{2}{*}{ P-value } \\
\hline & Mean \pm SD & Range & & \\
\hline \multicolumn{3}{|l|}{ Fathers' education: } & \multirow{6}{*}{$\begin{array}{l}\text { Independent } \\
\text { samples } \\
\text { t-test }\end{array}$} & \multirow{3}{*}{$0.672 \neq$} \\
\hline $\begin{array}{l}\text { Low level of education } \\
\text { ( basic, secondary, and technical } \\
\text { education) }\end{array}$ & $53.40 \pm 6.17$ & $46-65$ & & \\
\hline $\begin{array}{l}\text { High education (university and post } \\
\text { graduate degree) }\end{array}$ & $54.69 \pm 8.11$ & $35-68$ & & \\
\hline \multicolumn{3}{|l|}{ Fathers' occupation: } & & \multirow{3}{*}{$0.611 \neq$} \\
\hline Employer & $53.74 \pm 7.15$ & $35-68$ & & \\
\hline Skilled worker & $55.43 \pm 8.22$ & $46-65$ & & \\
\hline
\end{tabular}

$\neq P$-value is un-statistically significant difference at $>0.05$

Table (1); revealed the distribution of the studied children regarding to Socio-demographic characteristics. It was found that more than half of the studied children $(51.1 \%)$ were $6-17$ years and nearly half $(48.9 \%)$ were less than 6 years but more than two thirds $(72.3 \%)$ of the studied children were male. Regarding to residence more than three quarters $(80.9 \%)$ of the children were from urban localities and slightly more than half of family $(51.1 \%)$ had 3 or more children. Concerning the birth order; the table illustrated that $(46.8 \%)$ of the children were considered the first born in the family. More than one quarter $(29.8 \%)$ of the studied children diagnosed at first and third year of life. According to parents' education; the table cleared that $(63.8 \%)$ of fathers and $(61.7 \%)$ of mothers had university levels of education. On the other hand about three quarters $(74.5 \%)$ of fathers were employees, and only $(4.3 \%)$ were dead but more than half $(55.3 \%)$ of mothers were employees.

Figure (1); illustrated the distribution of the studied children related to consanguinity degree between parents. It was found that the majority of parents (85.1\%) hadn't consanguinity degree while (14.9\%) from them had consanguinity from first degree Figure (2); illustrated the distribution of the studied children related to family history of Autism and degree of relatives. It was found that the vast majority of the studied children $(97.9 \%)$ hadn't family history of Autism and only (2.1\%) had family history of Autism from first degree of consanguinity.

Table (2); cleared the distribution of studied children mothers' regarding to risk factors. It was found that the vast majority of mother's children $(95.7 \%)$ hadn't history of eclampsia. According to drug used during pregnancy without physician consultation; (14.9\%) of mothers were took analgesic drug without physician consultation. Slightly more than half $(51.1 \%)$ were exposed to radiology but only $(4.2 \%)$ exposed to $\mathrm{x}$ ray and more than half $(54.2 \%)$ of mothers were exposed from 1-3 times during pregnancy. Also this table showed that; more than two thirds $(68.1 \%)$ of mother's age during the index child were less than 30 years.

Table (3); showed the distribution of the studied children related to risk factors. It was found that the majority of the studied children (91.6\%) hadn't another disability with autism while $\mathbf{( 4 . 2 \% )}$ had Dawn's syndrome and (4.2\%) Mental Retardation (MR).. The majority of the studied children $(\mathbf{8 3 . 0 \%})$ not admitted to incubator; this table illustrates that; more than half of the studied children $\mathbf{5 1 . 1 \%}$ ) had history of watching T.V under the age of 3 years and more than two fifth $\mathbf{( 4 5 . 8 \% )}$ ) of them were watched T.V from 3-6 hours daily. Half of these children $(50.0 \%)$ watched songs and cartoon program and only $\mathbf{( 4 . 2 \% )}$ watch cartoon program. As regarding to the relationship between the parents the table cleared that, more than two thirds $\mathbf{( 7 0 . 2 \%}$ ) had good relation. Table (4); illustrated the relation between total score of mother's knowledge about Autism in pre, post and follow-up test. It was found that there was an improvement of mother's knowledge in immediate post-test while slightly declined after 3 months (follow-up test). Finally the table indicated that highly statistically significant difference between mother's knowledge in pre, and immediate post-test $(\mathrm{P}=0.000)$, while there was statistically significant difference between pre-test and follow-up $(\mathbf{P}=$ 0.016).

Table (5); reflected the relation between total score of father's knowledge about Autism in pre, post and follow-up test. It was found there was an improvement of father's knowledge about Autism in immediate post-test while slightly declined after 3 months (follow-up test). Finally the table indicated that there was highly statistically significant differences between father's knowledge about Autism in pre, and immediate post-test $(\mathrm{P}=0.000)$, 
while there was statistically significant difference between pre-test and follow-up $(\mathbf{P}=\mathbf{0 . 0 1 9})$

Table (6); demonstrated the relation between total score of mother's knowledge, and their education, and occupation level. It was found that the mothers who had high education were more knowledgeable (mean \pm SD 12.69 \pm 5.65) than the mothers had low level of education (mean \pm SD $5.78 \pm 5.39$ ). So that this table indicated that there was highly statistically significant difference between mother's knowledge and their education level $(\mathrm{P}=0.000)$. Also the table showed that; the employed mothers were more knowledgeable (mean \pm SD 12.04 \pm 7.44) than housewives (mean \pm SD $7.35 \pm 3.84$ ) so that this table indicated that there was statistically significant difference between mother's knowledge and their occupation $(\mathbf{P}=\mathbf{0 . 0 1 4})$.

Table (7); figured the relation between total score of father's knowledge, and their education, and occupation level. It was found that no difference between the fathers who had high level of education (mean \pm SD 8.25 \pm 6.39) and low level of education (mean \pm SD 3.90 \pm 2.42); so that this table indicated that there was no statistically significant difference between father's knowledge and their education level $(\mathbf{P}=\mathbf{0 . 0 5 2})$. Also the table cleared that; no difference between fathers who were employed and skilled worker in their knowledge (mean \pm SD 6.71 \pm 7.67) and (mean \pm SD $6.53 \pm 4.88$ ) respectively so that this table indicated that there was no statistically significant differences between father's knowledge and their occupation $(\mathbf{P}=\mathbf{0 . 4 9 1})$.

Figure (3); revealed the relation between Parental Stress Scale for mothers in pre, post and follow-up test. It was found that there was highly statistically significant differences between Parent Stress for mothers in pre and immediate post test $(\mathrm{P}=0.000)$; while no statistically significant difference between pre and follow-up test $(\mathbf{P}=\mathbf{0 . 1 5 2})$.

Figure (4); demonstrated the relation between Parental Stress Scale for fathers in pre, post and follow-up test. It was found that there was highly statistically significant difference between Parent Stress for fathers in pre and immediate post test $(\mathbf{P}=$ 0.002); while there was no statistical significant difference between fathers' stress in pre and followup test $(\mathbf{P}=\mathbf{0 . 4 1 7})$.

Table (8); illustrated the relation between Parent stress for mothers, and their education and occupation level. It was found that there was no obvious difference between parent stress for mothers and their education from high and low level of education respectively $\mathbf{( 5 3 . 4 5} \pm \mathbf{6 . 1 5}$ and $\mathbf{5 6 . 2 8} \pm$ 5.76) ; so there was no statistically significant difference between them $(\mathbf{P}=\mathbf{. 0 . 1 2 3})$. Also this table observed that no difference between parent stress for mothers and their occupation from employers mothers' and housewives respectively $\mathbf{( 5 4 . 5 8} \pm \mathbf{5 . 7 2}$ and 54.65 $\pm \mathbf{6 . 8 1})$; so there was no statistically significant difference between them $(\mathbf{P}=\mathbf{0 . 9 6 9})$.

Table (9); showed the relation between Parent stress for father, and their education and occupation level. It was found that there was no difference between parent stress for fathers and their education from high and low level of education respectively (53.40 \pm 6.17 and 54.69 \pm 8.11$)$; so there was no statistically significant difference between them $(\mathbf{P}=\mathbf{. 0 . 6 7 2})$. Also this table cleared that there was no difference between parent stress for fathers and their occupation from employers fathers' and skilled workers respectively $(\mathbf{5 3 . 7 4} \pm \mathbf{7 . 1 5}$ and $\mathbf{5 5 . 4 3} \pm \mathbf{8 . 2 2})$; so there was no statistically significant difference between them $(\mathbf{P}=\mathbf{0 . 0 6 1 1})$.

\section{Discussion:}

Autism Spectrum Disorders (ASDs) is a lifelong disability. It therefore requires continuous treatment and education in residential settings. Caregivers of children with autism spectrum disorder (ASDs) have experience of mental illnesses and stress at a greater rate than the general population. Thus supporting the family and ensuring its emotional and physical health is an extremely important aspect of overall management of ASDs (Rozga et al., 2011).

The current study revealed that, slightly more than half $(51.1 \%)$ of studied children were $\geq 6$ years; this finding might be due to the autism is not a new disorder, but present from several years. This result similar to Hsu et al., (2011) who found the autism more prevalent among younger group and Barnevik et al., (2008) who said the awareness of ASDs has resulted in increasing numbers of children being diagnosed at young ages

The findings of the present study showed that, more than two thirds of the children were males $\mathbf{( 7 2 . 3 \% )}$. In Upper Egypt the families who have disabled child may have a shameful feeling and additionally the parents are more important for caring of males than females so that the percentage of male was appeared than females. The finding of Abdelaziz, (2011) was in agreement with the present study who conducted a study in Egypt, reported that male children had a higher prevalence rate of autism than females. Also the finding of the current study was in agreement with Bolte \& Poustka, (2003) and Stuart \& McGew, (2009) who reported that males are several times more likely to be affected by autism than females. According to the Centers for Disease Control and Prevention CDC, (2009), estimated the number of male to female children with Autism spectrum 
disorders (ASDs) range between 3 to 1 or 4 to 1 and these gender differences are fairly consistent across ethnicities. On the other hand; the study of The Effects of Sex Differences and Cohabitation Status on Parental Stress in Parents of Children Diagnosed with Autism by Schneider, (2010) found that; the majority of the participants were females $(\mathbf{8 4 . 6 \%})$, and $\mathbf{( 7 . 1 \% )}$ were males.

As regards to the residence, more than three quarters $(80.9 \%)$ of autistic children were more prevalence among families living in urban areas and only (19.1\%) from rural areas, in rural area the people don't care for autistic children because there no enough services for these children. This study was in the same line with $\mathbf{H s u}$ et al., (2011) who reported that, the more population in metropolitan areas had a higher prevalence of autistic cases than the rural areas in Taiwan.

According to birth order; the current study cleared that more than two fifth $(46.8 \%)$ of studied children are considered the first born in the family. This result was disagreed with Gardener et al., (2009) who found that, the autistic disorder was associated with later born child ( $\geq$ third). Also Lin et al., (2008) reported that the highest percentage of children with autism was found among extended families in Taiwan.

More than one quarter $(29.8 \%)$ of autistic children in this study were diagnosed between the first and third year of life in this study; this might be the most of parents were highly educated, more knowledgeable and highly skillful for caring children. This finding was similar to the study conducted by El-Baz et al., (2011) in Ain Shams at Egypt; who conducted study of Risk factors for autism which indicated to (46.0\%) of autistic patients presented at age between one and half years.

The results of the current study showed that, more than three fifth $(63.8 \%)$ of fathers and mothers $(61.7 \%)$ had university levels of education; this might be the educated parents had awareness and good observation for any signs or change of child. These findings were consistent with study conducted by lin et al., 2008 and Schneider, (2010) who reported that, more than half of fathers and mothers were highly educated. The present study also agreed with the results of (Twoy et al., 2008) who found that (35.0\%) of autistic parents' children had completed four year of college, another $(40.0 \%)$ held master degrees and $(13.0 \%)$ held a doctoral degree and Sasanfar et al., (2010) in Iran revealed that, the most majorities of autistic children's parents had high level of education. Although this study showed that, about three quarters $(74.5 \%)$ of fathers were employed, and more than half $(55.3 \%)$ of mothers were employed. This result disagreed with the study demonstrated by
Grant and Ramcharan (2001) highlighted that mothers having a disabled child prevent them from seeking employment. Also Rai et al., (2012) who indicated that, the children of families with lower income and their parents' with manual occupations were at higher risk of ASDs.

The present study illustrated that the majority of parents $(85.1 \%)$ hadn't consanguinity degree while $(14.9 \%)$ from them had consanguinity from first degree (cousin). This might be the most of parents were highly educated from urban area were aware for dangerous of consanguinity marriage. The finding of El-Baz et al., (2011) was consistent with the present study which reported $(13.0 \%)$ from the sample had positive consanguinity degree.

Also this finding was in the same line with the study of prevalence of autism in children born to Somali parents living in Sweden by (Barnevik et al., 2008) who reported that Consanguinity was reported in the records for three individuals from 17 cases represented $(17.6 \%)$, parents being first cousins for one child and second cousins for another; a more remote relationship was declared for the third. Moreover this study disagreed with the study of Autism in Saudi Arabia: Presentation on Clinical Correlates and Comorbidity conducted by Al-Salehi et al., (2012) who reported that, 14 of 49 from studied sample represent (28.5\%) were consanguineous marriages.

According to family history; the results of the present study indicated that; the vast majority $(97.9 \%)$ of studied children hadn't family history of autism and only $(2.1 \%)$ had from first degree. Boyle et al., (2005) which mentioned that; the family history rate of autism is within the range $(2-8 \%)$. This finding was consistent with study demonstrated by $\boldsymbol{A} \boldsymbol{b d}$ Elhameed et al., (2011) who reported that, only $(2.5 \%)$ had family history; while differed from study conducted by El-Baza et al., (2011) who found that statistically significant difference with family history and autism.

According to obstetrical history; the present study found that all mothers of studied children hadn't any history of rubella, diabetes, thyroid and infectious diseases while only $(4.3 \%)$ were exposed to eclampsia. This result agrees with the study conducted by El-Baz et al., (2011) in Egypt who revealed that no significant difference was found between cases and controls as regards prenatal factors (Hypertension). While disagreed with (DM, and infection). On the other hand the findings disagreed with the study of pregnancy and birth complication in autism and liability to the broad autism phenotype by Zwaigenbaum et al., (2002) who reported that, no statistically significantly difference associated with pregnancy and birth complication. 
The present study cleared that, more than two thirds $(68.1 \%)$ of mother's age during the index pregnancy were less than 30 years and only $(6.4 \%)$ were up to 35 yrs. This finding disagreed with study applied by El-Baza et al., (2011) in Ain shams who found that, $(23.0 \%)$ of children mothers' were up to 35 years during pregnancy. Also disagrees with the study of paternal age increases the risk for autism in an Iranian population sample applied by Sasafanar et al., (2010) who indicated that, there was a significant association between higher paternal age,

Concerning of autistic child had another disability or congenital anomalies in the present study, the majority of them $(91.6 \%)$ hadn't another disability while (4.2\%) had Dawn's syndrome and (4.2\%) MR. This finding was disagreement with the study by Dawson et al., (2008) who reported that, (75\%) to $(80.0 \%)$ of autistic children have a certain degree of MR.

As regarding to history of the child to watching T.V under the age of 3 years and the period of watching; the current study cleared that; more than half of the studied children $(51.0 \%)$ had history of watching T.V under the age of 3 years. This finding may be due to the most of children mothers' were employees so that they were busy with housework after coming back from the job. Waldman and Adilov, (2006) in Indiana conducted a study of "Does television causes autism?" the study investigated the possibility of cause autism with watching TV and showed that early childhood television viewing is a trigger for autism; so that the children shouldn't watch T.V before the age of three.

As regarding period of watching T.V; the present study indicated more than two fifth $(45.8 \%)$ of the children who watched T.V setting in front of it from 3-6 hours daily. Munasib \& Bhattacharya, (2010) who mentioned that study of early and middle childhood television watching and child cognitive outcome and they found strong evidence of negative correlations between hours of television watched and cognitive status. On the other hand The American Association of Pediatrics and many other experts recommend no television viewing under the age of 2 years. For 2-3 year old recommended limiting television viewing to half an hour per day and 1 hour per day is enough for 3-5 year old Smith, (2011).

According to the relationship between the parents of autistic children this study indicated that, more than two third of them $(70.2 \%)$ had good relation and more than one quarter $(29.8 \%)$ had bad relation. Moreover the social conditions surrounding the child are better predictors of the child's outcome than their early biological status measured by birth and pregnancy conditions. These conditions include favorable parental attitudes, low levels of family conflict, small family size, and a lower amount of stressful life experiences Rivers and Stoneman, (2003).

The present study reported that the mother's and father's knowledge about autism, signs and symptoms, methods of diagnosis and treatment, nutrition were poor before the application of the program in pre-test while improved after the application of the program (post test) in general but slight decline in their knowledge after three months from the program. So that the findings indicated that highly statistically significant difference between mothers' and fathers' knowledge about autism (Pvalue $=\mathbf{0 . 0 0 0}$ ) in pre and immediate post-test; while statistically significant differences in pre and followup (P-value $=\mathbf{0 . 0 1 4}$ and 0.016) respectively.

These finding were in the line with Winerman, (2004) and Catherine (2010) who indicated that highly statistically significant difference between the parents' knowledge about autism, in pre and posttest. Also the difference between the pre test, immediate post-test and follow up in the current study is in agreement with study conducted by Tonge et al., (2006), Matson et al., (2009), and Keen et al., (2010). This difference can be interpreted due to the educational program helped to improve knowledge in immediate post test and follow up.

As regards the relation between mother's knowledge and education, the current study indicated that, mothers who had high level of education were more knowledgeable than low level of education so that there was statistically significant difference between mother's knowledge and education $(\mathbf{P}$ value $=$ $\left.0.000^{*}\right)$. This difference may be due to the highly educated mothers were more knowledgeable and had different methods for knowing about autism.

Also the study cleared that, the employed mothers were more knowledgeable than housewives so that there was statistically significant difference between mother's knowledge and occupation ( $P$ value $=$ $\left.0.014^{*}\right)$. might be due to the employed mothers were more contacted with others people from different jobs and highly experienced; therefore give more opportunity for talking about autism while the housewives mothers were closed with themselves.

The present study assessed the stress level among parents' of autistic children before, immediately application of the program and after 3 months. This study showed that, the mothers' and fathers' of autistic children had experienced a high level of stress before intervention. While the stress level decreased in immediate post test. On the other hand the stress level was slightly higher after three months (follow-up). The possible explanation regarding the 
high level of stress in parents could be interpreted that autism is a pervasive developmental disorder so autistic children have more severe form of disability. Moreover children with autism display features such as impulsivity, hyperactivity, irritability, and aggressiveness, which are characterized by unpredictability and volatility therefore the parents need to continuous support (Keltner et al., 2011).

Moreover the current study illustrated that; there was highly statistically significant difference between pretest and immediate post-test for mothers and fathers stress respectively $(\mathrm{P}$-value $=0.000 * \& 0.002 *)$ while no statistically significant difference between pre-test and follow-up respectively for mothers and fathers $(\mathrm{P}$-value $=0.152 \& 0.417)$. These finding agreed with study conducted by Mori et al., (2009) who found that there were significantly elevated parental stress levels in Japanese parents of children with autism before intervention. Also was in agreement with Koydemir and Tosun, (2009) who stated that all mothers of children with autism experienced stress. Furthermore, Tomanik et al., 2004 \& Duarte et al., (2005) and Fiske, (2009) who found that parents of children with ASDs experienced higher levels of stress, compared to parents of typically developing children. Also Rozga et al., (2011) who reported that, caregivers of children with autism spectrum disorder (ASDs) had experience mental illnesses and stress at a greater rate than the general population.

According the relation between parents' stress (mothers and fathers), and their education and occupation level. This study cleared that; there were no statistically significant differences between parents stress, and their education and occupation respectively ( $\mathrm{P}$ value $=0.123$ and 0.969 ). These findings were in the same line with Tomanik et al., 2004 Koydemir and Tosun, (2009) who reported that, there was no statistically significant difference between parent stress for mothers and education. Finally the current study agreed with them there were no statistically significant differences between parents' education, occupation and stress in relationship with their children.

\section{Conclusion :}

Based on the results of the present study it can be concluded that there was improvement of parents' knowledge about autism in immediate post test and follow up; moreover the parents' stress level was decreased in immediate post test than pre test while the stress level again slightly increased during follow up test.

\section{Recommendations}

Based on the results of the present study, the researcher came up with the following recommendations :The study recommended that: Nursing staff should play a much greater role in supporting parents and providing them with important information through pediatrics clinics, Maternal and Child Health Centers (MCH), and continues health education programs should be implemented for parents about how to care and deal ideally with autistic children and they should be directed by the professional nurses for caregivers and the community in general.

\section{References:}

1. Abd Elhameed M. A., Abd Elbaky A. O., and Kamel E. A.,(2011): A Controlled Study of the Risk Factors and Clinical Picture of Children with Autism in an Egyptian Sample, Department of Neuropsychiatry, Minia University; Egypt , Egypt J Neurol Psychiat Neurosurg. 2011; 48(3): 271-276]

2. Abdelaziz T.A., (2011): Head-circumference and blood lead level in autistic children, published master degree, Faculty of medicine, Zagazig University. http//www.edu. eul.eg.

3. Allender J.A., Rector C. and Warner K.D., (2010): Community Health Nursing, Promoting and protecting the public's health, unit 6 , Promoting and protecting the health of aggregates with developmental needs, 7edition, 'Philadelphia, P: 608.

4. Al-Salehi S. M., Al-Hifthy E. H., and Ghaziuddin M., (2012): Autism in Saudi Arabia: Presentation, Clinical Correlates and Comorbidity, University of Michigan Medical Center, Journal of Transcultural Psychiatry,49,(5):110-120 Available at:www.sagepublications.com

5. American Psychiatric Association (APA), (2000): Diagnostic and Statistical Manual of Mental Disorders - fourth edition, Text Revision; (DSM-IV-TR); Washington, DC: American Psychiatric Press, (DSM-IV-TR).

6. Autism information Center, (2008): Autism Spectrum Disorders overview, Pp: 1-3. From http//: www.cdc.gov/ autism/overview.htm.

7. Autism Society, (2008): Improving the lives with all affected by autism, available at:http://www.autism-society.org

8. Barnevik M. O., Gillberg C., and Fernell E., (2008): Prevalence of autism in childrenborn to Somali parents living in Sweden: a brief report Developmental Medicine \& Child Neurology Volume 50, Issue 8, pages 598-601.

9. Berry J. O. and Jones W. H., (1995): The Parental Stress Scale: Initial psychometric evidence. Journal of Social and Personal 
Relationships, 12, 463-472. Available at http://www.personal.utulsa.edu/ iudyberry/parent.htm.

10. Bolte S., and Poustka F., (2003): Genetic, environmental and immunologic factors in the etiology of Autism Spectrum Disorders, Journal of Neuro-Embryology,2:175-179.

11. Bowden V.R. and Greenberg C.S, (2010): Children and Their families, The continuum of care, unit III, Managing health challenges, Autistic disorder, $2^{\text {nd }}$ edition, Philadelphia, Pp: 1580-84.

12. Boyle C., Van Naaeden Braun K., and YearginAllsopp M., (2005): The prevelance and the genetic epidemiology of developmental disabilities. Avaliable at: CDC-source for credible health information. http://www.cdc.gov/ncbddd/autism/index/html.

13. Burns C.E., Dunn A.M., Brady M.A. and Starr N.B., (2009): Pediatric Primary Care, unit 11, nursing care of the child with a health disorder, $4^{\text {th }}$ edition, China, P: 1704.

14. Catherine M., (2010): Behavioral Intervention for Young Children with Autism: A Manual for Parents and Professionals, journal of American Academy of child and adolescence psychology, 45(5): 56-78. www.sciencedirect.com

15. Centers for Disease Control \& Prevention (CDC), (2007): Autism Information Center, from http://www.cdc. org/ ncbddd/Autism.

16. Centers for Disease Control \& Prevention (CDC), (2009): Prevalence of autism spectrum disorders-Autism and Developmental Disabilities Monitoring Network, United States, Morbidity and Mortality, Weekly Report: Surveillance Summaries, 58, 1-20.

17. Centers for disease control and prevention $(C D C)$, (2010): Autism spectrum disorders, treatment, Pp: 1-6, Available at www.cdc.com

18. Dawson M., Mottron L., and Gernsbacher M.A., (2008): Learning in autism, In Byrne JH (ed.-in-chief), Roediger HL III (vol. ed.) Learning and Memory: A comprehensive Reference.2.Academic Press, Pp: 759-72.

19. Duarte C.S., Bordin I.A., Yazigi L., and Mooney J., (2005): factors associated with stress in mothers of children with autism. Autism; 9:416-427.

20. El-Baz, F., Ismael N. A., and Nour El-Din S. M., (2011): Risk factors for autism: An Egyptian study, Pediatrics, Community Department, Medical Genetics Center, Ain-Shams University, Egyptian journal of Medical Human Genetics, volume 12: Issues 1, P: 31-38.

21. Fiske K. E., (2009): A cross-Sectional Study Of Patterns Of Renewed Stress Among Parents Of
Children With Autism, Doctoral A Dissertation, Clinical Psychology, ProQuest LLC, Pp:29-34.

22. Gardener H., Spieglman D., and Buka L., (2009): Prenatal risk factors for autism: comprehensive meta-analysis, the British journal of psychiatry, 195: 7-14.

23. Grant G., and Ramcharan P., (2001): Views and experiences of people with intellectual disabilities and their families, the family perspective, journal of Applies Research in intellectual disabilities, 14:364-380.

24. Hales R.E., and Yudofsky S.C., (2004): The American psychiatric publishing textbook essentials of clinical psychiatry, $2^{\mathrm{n}}$ edition, Arlington, American psychiatric publishing, Pp: 100-110.

25. Hassan A.K., (2010): Study of knowledge, practices and attitudes of nursing students regarding pulmonary tuberculosis as a basis to develop, implement and evaluate an educational program for them in Assiut City, Doctoral A Dissertation, Assiut University, faculty of nursing.

26. Hsu S. W., Chiang P. H., Lin L. P., and Lin J. D., (2011): Disparity in autism spectrum disorder prevalence among Taiwan National Health Insurance enrollees: Age, gender and urbanization effects, Research in Autism Spectrum Disorders (6)836-841. http//www.autism society/org/site/page-server

27. Johnson C.P., \& Myers S. M., (2007): Council on children with disabilities, Identification and evaluation of children with autism spectrum disorders, Pediatrics; 120(5), 1183-1215.

28. Keen D., Couzens D., Muspratt S., Rodger S., (2010): The effects of a parent-focused intervention for children with a recent diagnosis of autism spectrum disorder on parenting stress and competence, Research in Autism Spectrum Disorders, Volume 4, (2): 229-241

29. Keltner N. L., Bostrom C. E., and McGuinness T.M., (2011): Psychiatric Nursing, Sixth edition, USA, Ch. 40, Child and Adolescent psychiatric Nursing, P:462.

30. Kliegman R.K., Jenson H.B., Behrman R.E. and Stanton B.F., (2007): Nelson Textbook of Pediatrics, Ch. 29, Pervasive Development Disorders and Childhood Psychosis, Autistic disorder, $18^{\text {th }}$ edition, U.S.A, Pp: 133-137.

31. Klossner N.J., and Hatfield N.T., (2010): Introductory maternity and pediatric nursing, Ch.42, the child with a psychosocial disorder, $2^{\text {nd }}$ edition, China, Lippincott William \& Wilkins, Pp: 937-39.

32. Koydemir S., and Tosum U. (2009): Impact of autistic children on the lives of mothers, 
Procedia Social and Behavioral Siences, 1: 2534 2540.

33. Levy S.E., Mandell D.S. and Schultz R.T., (2009): Autism, Lancet, 374(9701): 1627-3 8.

34. Lin C. R., Tsai Y. F., and Chang H.L., (2008): Coping mechanism of parents of children recently diagnosed with autism in Taiwan, a qualitative study, journal of Clinical Nursing, 17:2733-2740.

35. Matson M. L., Mahan S., and Matson J. L., (2009): Parent training: A review of methods for children with Autism Spectrum Disorders, Research in Autism Spectrum Disorders, 3, (4): 868-875.

36. Mori K., Ujiie T., Smith A., and Howlin P., (2009): Parental stress associated with caring for children with Asperger's or Autism, Pediatric international 51, 36370 doi: 10. 1111/j.1442200X.2008.02728.x @Japan Pediatric Society.

37. Munasib A., \& Bhattacharya S., (2010): Early and middle childhood Television watching and child cognitive outcome, Economic of Education Review, volume 29 (5) P: 873-883.

38. National Autism Association, (2010): What causes of autism, available at:http://www.nationalautismassociation.com

39. Rai D., Lewis G., Lundberg M., Araya R., svenssan A., (2012): Parental socioeconomic status and risk offspring Autism Spectrum Disorders in A Swedish population -based study, journal of American academy of child and adolescence psychiatry, volume 51(5): 467-476.

40. Rivers J.W., and Stoneman R., (2003): Health care transition, destinations unknown, pediatrics, 110:1307-1314.

41. Rozga A., Hutmant T., Young G. S., Rogers S. T., and Ozonoff S., (2011): Intersubjective disruptions and caregivers infant interaction in early autistic disorders, Research in Autism Spectrum Disorders, volume 5,(1): 408-417.

42. Sadack B.J. and Sadock.V.A., (2010): Kaplan \& Sadock's Synopsis of Psychiatry, Behavioral sciences/ clinical psychiatry, Vol. Ill, Ch: 42, Pervasive Development Disorders, $10^{\text {th }}$ edition, USA, Lippincott Williams \& Wilkins, Pp: 11911205.

43. Sasanfar R., Haddad S. A., Tolouei A., Ghadami M., and Santangelo S.,(2010): Paternal age increases the risk for autism in an Iranian population sample, Molecular Autism, $1: 2$.

44. Schneider T., (2010): The effects of sex differences and cohabitation status on parental stress in parents of children diagnosed with autism, published doctoral dissertation, philosophy psychology department, Walden university. ProQuest LLC.

45. Smith C., (2011): Television Watching: Practical Advice for Parents of Young Children, Articles Helpful information for parents and professionals, @The Hanen centre. All rights Reserved v3.2.0.

46. Stuart M., and McGrew J.H., (2009): Caregiver burden after receiving a diagnosis of an autism spectrum disorder, Research in Autism Spectrum Disorders; 3(1): 86-97.

47. Tomanik S., Harris G. E., and Hawkins J., (2004): The relationship between behavior exhibited by children with autism and maternal stress. Journal of intellectual and developmental disability, 29: 16-26.

48. Tonge B., Buereton A., Kiomall M., (2006): Effects on parental mental health of an education and skills training program for parents of young children with autism, journal of American Academy of child and adolescence psychiatry, volume 45(5): 561-569.

49. Twoy R., Connolly P.M., and Novak J.M., (2008): Coping strategies used by parents of children with autism, journal of the American Academy of Nurse Practitioners, 19:251-260.

50. US Census Bureau, Population Estimates, (2008): Available at http:// CureResearch.com/ TM Health Grades, Inc. All rights reserved.

51. Videbeck S.L., (2008): Psychiatric-Mental Health Nursing, Ch: (20), Child and Adolescent Disorders, $4^{\text {th }}$ edition, China, P: 435.

52. Waldman C., and Adilov N., (2006): Does Television Cause Autism? Johnson Graduate School of Management and Department of Economics, Cornell and Indiana University. Available at: http://www.sciencedirect.com

53. Winerman L., (2004): Effective education for autism, American Psychological Association, volume 35(11): 46 .

54. Zwaigenbaum L., Szatmari P., Jones M. B., Bryson S. E., Maclean J. A., Mahoney W.J., Bartolucci G., and Tuff L., (2002): pregnancy and birth complication in autism and liability to the broad autism phenotype, journal of the American Academy of child and Adolescence psychiatry, volume 41: Issues 5 , P: 572-579. 